\title{
Dynamics of m6A RNA Methylome on the Hallmarks of Hepatocellular Carcinoma
}

\author{
Enakshi Sivasudhan 1,2, Neil Blake'2, Zhi-Liang Lu'1,3, Jia Meng ${ }^{1,3}$ and Rong Rong 1,3* \\ ${ }^{1}$ Department of Biological Sciences, Xi'an Jiaotong-Liverpool University, Suzhou, China, ${ }^{2}$ Department of Clinical Infection, \\ Microbiology and Immunology, Institute of Infection, Veterinary and Ecological Sciences, University of Liverpool, Liverpool, \\ United Kingdom, ${ }^{3}$ Institute of Integrative Biology, University of Liverpool, Liverpool, United Kingdom
}

OPEN ACCESS

Edited by:

Rui Henrique,

Portuguese Oncology Institute,

Portugal

Reviewed by:

Hong Zheng,

Stanford University, United States

Lucia Coscujuela Tarrero,

Italian Institute of Technology (IIT), Italy

*Correspondence:

Rong Rong

Rong.Rong@xjtlu.edu.cn

Specialty section:

This article was submitted to

Epigenomics and Epigenetics,

a section of the journal

Frontiers in Cell and Developmental

Biology

Received: 16 December 2020

Accepted: 23 February 2021

Published: 01 April 2021

Citation:

Sivasudhan E, Blake N, Lu Z-L, Meng $J$ and Rong R (2021) Dynamics

of m6A RNA Methylome on

the Hallmarks of Hepatocellular

Carcinoma

Front. Cell Dev. Biol. 9:642443. doi: 10.3389/fcell.2021.642443
Epidemiological data consistently rank hepatocellular carcinoma (HCC) as one of the leading causes of cancer-related deaths worldwide, often posing severe economic burden on health care. While the molecular etiopathogenesis associated with genetic and epigenetic modifications has been extensively explored, the biological influence of the emerging field of epitranscriptomics and its associated aberrant RNA modifications on tumorigenesis is a largely unexplored territory with immense potential for discovering new therapeutic approaches. In particular, the underlying cellular mechanisms of different hallmarks of hepatocarcinogenesis that are governed by the complex dynamics of m6A RNA methylation demand further investigation. In this review, we reveal the up-to-date knowledge on the mechanistic and functional link between m6A RNA methylation and pathogenesis of HCC.

Keywords: hepatocellular carcinoma, epitranscriptomics, m6A RNA methylation, cancer hallmarks, writers, erasers, readers

\section{INTRODUCTION}

The advent of advancements in next-generation sequencing technologies along with the launch of highly specific antibodies capable of identifying chemically modified nucleotides broke new ground for RNA methylation, recently coined "epitranscriptomics," to gain prominence as a dynamic and reversible modification, analogous to epigenetic regulations. While previous studies have largely focused on the genetic and epigenetic factors that contribute to hepatocellular carcinoma (HCC), research into deciphering the role of epitranscriptomics in triggering liver-related malignancies is still in its infancy. Thus, the dynamics of m6A RNA methylation on the molecular pathogenesis of HCC is an emerging field that requires extensive research, with immense potential to unlock new therapeutic targets to combat hepatocarcinogenesis.

\section{HEPATOCELLULAR CARCINOMA}

Hepatocellular carcinoma accounts for over $80 \%$ of hepatic neoplasms worldwide, imposing heavy disease burden by being the fourth most common cause of cancer-associated mortality worldwide (El-Serag and Rudolph, 2007; Fitzmaurice et al., 2019). The HCC incidence has been estimated to be more prevalent in males than females and widespread in certain regions including middle and western Africa, eastern and southern Asia, Polynesia, and Melanesia (Ferlay et al., 2010). Several risk 
factors contribute to HCC, among which chronic alcohol consumption, cirrhosis, viral hepatitis (due to infection with hepatitis virus $\mathrm{B}$ and $\mathrm{C}$ ), non-alcoholic fatty liver disease (NAFLD), and ingestion and exposure to aflatoxin and aristolochic acid majorly contribute toward the onset of hepatocarcinogenesis (Yang and Roberts, 2010). Chronic hepatitis $\mathrm{B}$ and $\mathrm{C}$ account for the most frequent etiologies especially in particular geographical locations (such as Oceania, western sub-Saharan Africa, and central Asia) with inadequate medical resources and also the predisposition to gradual hepatic damage and ensued cirrhosis and HCC (Bosch et al., 2004; Stanaway et al., 2016). Pathologically, the regenerating nodules synthesized during cirrhosis create a favorable microenvironment for the transformation of dysplastic hepatocytes to neoplastic lesions ultimately leading to HCC (Alqahtani et al., 2019). In addition, the manifestation of HCC is seldom reported in congenital hepatic fibrosis, ataxia telangiectasia, familial cholestatic cirrhosis, familial polyposis coli, fetal alcohol syndrome, and neurofibromatosis (Leong and Leong, 2005).

Surveillance for HCC, principally in high-risk individuals, includes ultrasonography and biomarker testing (Yang and Roberts, 2010). While emerging research shows several promising biomarkers, pertaining to HCC diagnosis, prognosis, and clinical staging, such as vascular endothelial growth factor (VEGF; Biselli-Chicote et al., 2012), epidermal growth factor (EGF; Kedmi et al., 2015), platelet-derived growth factor (PDGF; Campbell et al., 2005), insulin-like growth factor (IGF; EnguitaGermán and Fortes, 2014), mammalian target of rapamycin (mTOR), and microRNAs (Mínguez and Lachenmayer, 2011; Okada et al., 2015), currently alpha-fetoprotein (AFP) is the only clinically approved serological biomarker (Beudeker and Boonstra, 2020). In fact, high expression levels of EGF and VEGF that promote proliferation and angiogenesis, respectively, have been associated with early recurrence of HCC, while TGF and PDGF receptor protein overexpression has been shown to activate profibrotic pathways that induce liver tumorigenesis (Campbell et al., 2005; Biselli-Chicote et al., 2012; Kedmi et al., 2015). Patients diagnosed with early-stage HCC opt for curative treatment options including surgical removal, orthotopic liver transplantation, or percutaneous ablation, usually performed with radiofrequency ablation or percutaneous alcohol injection. For patients with unremovable tumors, transarterial chemoembolization, carried out by infusing a concoction of chemotherapeutic agents, and transarterial radioembolization, involving treatment with radioactive particles are recommended. Besides, treatment options for patients with advanced stages of cancer include multikinase inhibitors such as sorafenib, lenvatinib, and regorafenib (Llovet et al., 2008; Yang and Roberts, 2010).

The initiation and progression of HCC are facilitated by various genetic and epigenetic alterations, which are built up in hepatocytes, eventually leading to malignant transformation as a result of the conversion of proto-oncogenes to oncogenes and the loss of functional mutation or dosage changes of tumor suppressor genes. Genetic abnormalities include chromosomal translocation, single-nucleotide polymorphisms, and targeted gene loss and deletion (Singh et al., 2018). Epigenetic changes, on the other hand, inflict no permanent genetic alterations; instead, they affect gene transcription and chromatin integrity. Epigenetic modifications that drive HCC include genespecific DNA hypo- and hypermethylation, global genomic hypomethylation, aberrant histone modifications, and altered expression of microRNA (Leong and Leong, 2005; Libbrecht et al., 2005). Furthermore, deregulation of signal transduction pathways that govern cell cycle, proliferation, differentiation, and apoptosis, including the Wnt/ $\beta$-catenin pathway, Ras/Raf/MAPK pathway, PI3/AKT/mTOR pathway, JAK/STAT pathway, and ubiquitin-proteasome pathway (UPP), can lead to onset of liver tumorigenesis (Alqahtani et al., 2019).

\section{HALLMARKS OF HEPATOCELLULAR CARCINOMA}

Hanahan and Weinberg comprehensively presented the exploration of distinct and complementary traits that trigger tumorigenesis and metastatic propagation by logically organizing them into major hallmarks to rationally appreciate the complexities of neoplastic maladies (Hanahan and Weinberg, 2000, 2011). These hallmarks of cancer are as follows: sustaining proliferative signaling, eluding growth suppressors, evading immune destruction, facilitating replicative immortality, aiding in tumor-promoting inflammation, triggering invasion and metastasis, prompting angiogenesis, inducing genomic instability, preventing cell apoptosis, and deregulating cellular energetics (Hanahan and Weinberg, 2011). The hallmarks of cancer with regard to HCC are reviewed below and summarized in Figure 1.

Sustaining mitogenic signaling and evading growth suppressors in tumor cells are feasibly the most fundamental characteristics of tumor cells, unlike in normal cells that regulate cell homeostasis, especially pertaining to releasing growth-promoting signals (Hanahan and Weinberg, 2011; Sever and Brugge, 2015). For instance, HCC occurs largely as a result of uninhibited cellular proliferation resulting from a series of dysregulations in normal cell cycle regulators such as cyclin-dependent kinases (CDKs). Given the unique regenerative aptitude of hepatocytes, any reprobate cell proliferation, upregulation of CDKs, or alterations in CDK-related downstream signaling pathways and CDK inhibitors could potentiate the onset of hepatocarcinogenesis (Shen et al., 2019).

The role of the immune system in eradicating certain neoplasia and micrometastases is an area that demands further researching. Owing to the ever-alert surveillance nature of immune cells in eliminating tumor cells, it is worth exploring the potential mechanisms that solid tumors have acquired in successfully evading immunological destruction. In HCC, immune checkpoint inhibitors such as CTLA4 and PD-L1 regulate the immunosuppression of chronic inflammation brought about by persistent expression of certain cytokines and immune cell recruitment (Makarova-Rusher et al., 2015; Xu et al., 2018). Contrary to previous beliefs that immune responses largely represented an attempt to 


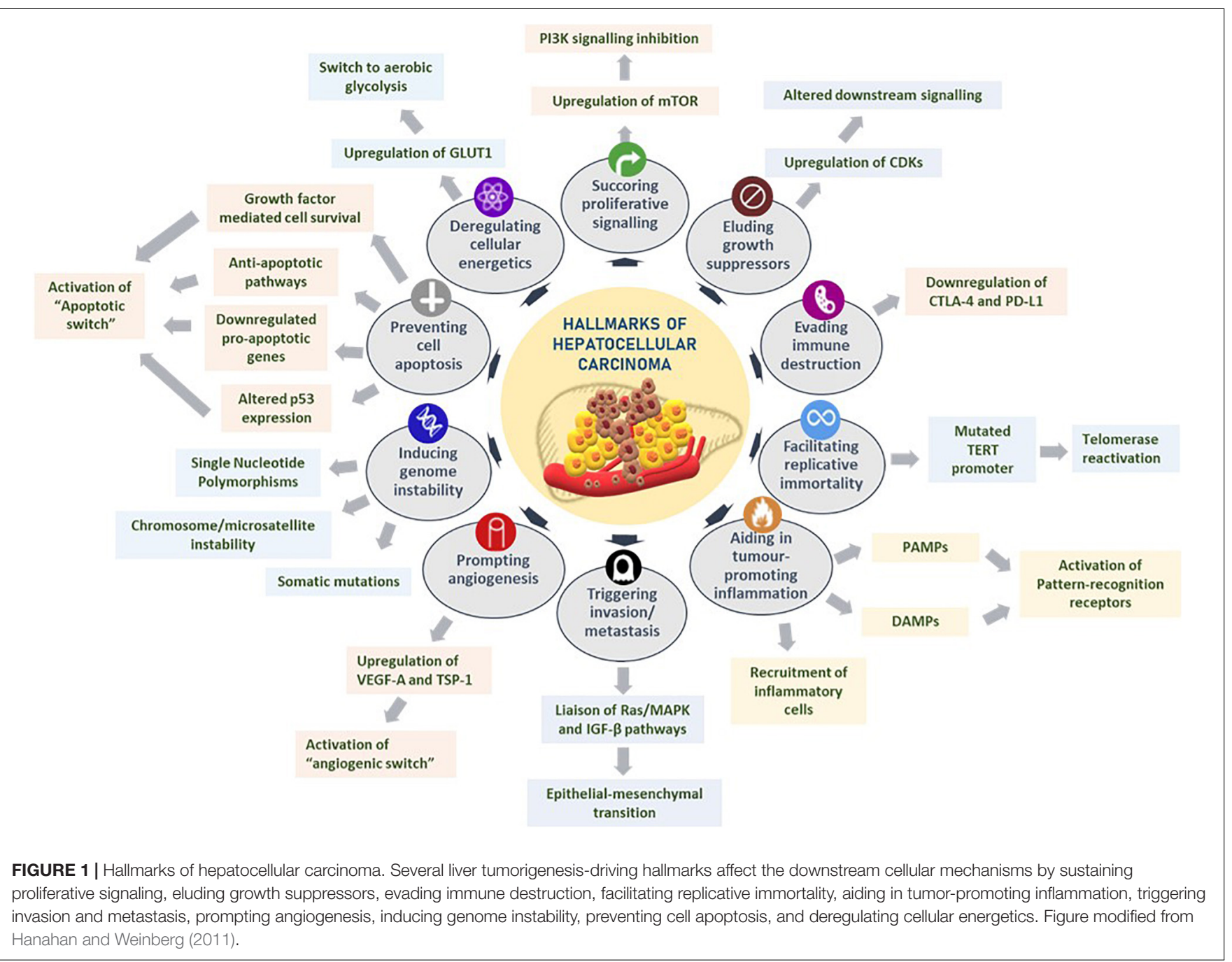

eliminate tumorigenesis, an ever-growing assemblage of scientific evidence suggests the paradoxical effect of tumor-induced inflammation in aiding neoplasias (DeNardo et al., 2010; Qian and Pollard, 2010). HCC-associated inflammation could be chiefly attributed to recruitment of inflammatory cells in the tumor microenvironment, extrinsic pathways that activate pattern recognition receptors by pathogen-associated molecule patterns, or damage-associated molecule patterns (DAMPs) released from liver cells undergoing apoptosis (Yu et al., 2018).

Tumor cells ensure continued survival by withstanding two crucial aspects that limit unlimited replicative potential in normal cells: senescence and crisis/apoptosis. It has been observed in cirrhotic liver cells that telomerase, an enzyme that prevents telomere shortening and ensuing cellular senescence, has an impaired activity coupled with subsequent shortening of telomeres implicating senescence of hepatocytes (Nault et al., 2019). To circumvent this and enable replicative perpetuity, telomerase reactivation is elicited through aberrant mutations in TERT promoter, leading to uncontrolled cell proliferation and subsequent HCC development (Donaires et al., 2017; Nault et al., 2019).
The multistep mechanism of invasion and metastasis is broadly regulated by epithelial-mesenchymal transition (EMT), heterotypic involvement of neoplastic stromal cells, and plasticity in the invasive growth properties disseminated by cancer cells (Hugo et al., 2007; Klymkowsky and Savagner, 2009; Egeblad et al., 2010). It has been proposed that in HCC, signaling through the Ras/MAPK pathway could liaise with the TGF$\beta$ signal transduction pathway in driving the shift from EMT, rendering tumor cells their mobility (Matsuzaki et al., 2000). Another hallmark of cancer, inducing angiogenesis, involves tumor-associated neovasculature that activates an "angiogenic switch" through the regulation of countervailing inducers and inhibitors, such as VEGF-A and thrombospondin-1, respectively, Hanahan and Weinberg (2011). Given the high invasive nature of HCC, it is not surprising to observe VEGF overexpression in the precancerous stages of dysplastic and cirrhotic liver tissues further to a strong correlation of VEGF expression and tumor grading of HCC (Hamdy et al., 2020).

Acquisition of genomic instability could convene selective advantage on neoplastic cells, enabling them to outgrow and dominate in a tumor microenvironment niche. Premalignant 
cells drive tumorigenesis by enhancing their sensitivity to mutagenic agents and compromising the "surveillance systems" that monitor cellular genomic integrity (Jackson and Bartek, 2009). Notably in HCC, genetic alterations are instigated by chromosome and microsatellite instability, accumulated somatic mutations, single-nucleotide polymorphisms, and deregulated signaling pathways (Niu et al., 2016; Rao et al., 2017). Resisting cell death is another crucial hallmark of tumorigenesis. While programmed cell apoptosis, resulting from certain elevated oncogenic signaling mechanisms and hyperproliferation-associated DNA damage, functions as a natural barrier to carcinogenesis, certain tumors eventually progress to high-grade malignancy and induce drug resistance, through an "apoptotic switch" (Adams and Cory, 2007; Hanahan and Weinberg, 2011). Especially in HCC, apoptosis-associated mechanisms are governed by attenuation of p53 function through telomere-induced chromosomal instability (Farazi et al., 2006), downregulation of pro-apoptotic genes such as B cell lymphoma 2 (Mott and Gores, 2007), growth factor-mediated cell survival (Llovet and Bruix, 2008), and overactivation of anti-apoptotic pathways associated with fas pathway inhibitors (Lee et al., 2001).

Tumor energy metabolism, an emerging hallmark, confers the metabolic preferences of cancer cells to favor aerobic glycolysis, famously characterized as the Warburg effect (Vander Heiden et al., 2009). Gluconeogenesis in HCC is driven by upregulating facilitative glucose transporters, notably GLUT1 (Yamamoto et al., 1990), significant elevation of hypoxic regulators such as HIF-1 $\alpha$ (Yang et al., 2014), and expression of rad and myc oncogenes that fuels glycolysis (Tiniakos et al., 1989).

Tumor pathogenesis encompasses a complex network of regulatory pathways involving various genetic, epigenetic, and epitranscriptomic mechanisms. Aberrant epitranscriptomic RNA modifications have also been shown to drive tumorigenesis due to dysregulation of RNA processing, polyadenylation, translation initiation, splicing, stability, and localization, which affect translation of tumor suppressors and oncogenes (Ferlay et al., 2010). Since each cancer type differs from the other, it is not surprising that different tumor promoters may activate different oncogenic pathways, directly or indirectly affecting RNA modifications, such as $\mathrm{m} 6 \mathrm{~A}$ and thereby their protein levels. It is evidenced that downregulation of RNA m6A modification can promote tumor progression in several types of cancers, such as glioblastoma, endometrial tumors, and leukemia (Yang and Roberts, 2010). Therefore, it is crucial to explore the relationship between aberrant RNA m6A modifications and hepatocarcinogenesis to better understand the disease etiopathogenesis.

\section{M6A RNA MODIFICATION AND ASSOCIATED REGULATORS}

First identified in $1970, N^{6}$-methyladenosine (m6A) is the most profuse and reversible internal modification omnipresent in eukaryotic mRNA and has been the focus in the emerging field of epitranscriptomics (Wu et al., 2016). While research has previously explored the crucial role of epigenetic regulation, pertaining to DNA and histone methylation, the dynamic function of m6A RNA modification is a relatively novel and largely unexplored territory, with regard to discovering mechanisms of gene expression regulation (Strahl and Allis, 2000; Suzuki and Bird, 2008; Wu et al., 2016). With the advent of new next-generation sequencing approaches such as MeRIPseq, over 12,000 highly conserved methylated peaks have been identified in human and mouse transcriptomes, revealing the correlation between $\mathrm{m} 6 \mathrm{~A}$ abundance and the structural and functional aspects of a specific gene. m6A modification refers to the addition of a methyl group to the nitrogenous base present at the sixth position of the adenine residue in the RNA (Figure 2; Desrosiers et al., 1974). With an approximate estimate of 0.1$0.4 \%$ of adenosines subjected to alterations, an average of two to three m6A-modified sites have been predicted to be present in every mRNA transcript (Wei et al., 1975). Topological analysis has indicated that methylation occurs mainly near the $3^{\prime}$-UTR region, on adenosine residues presenting in a consensus motif of RRm6ACH ( $\mathrm{R}=\mathrm{G} / \mathrm{A}, \mathrm{H}$ = A/C/U; Figure 2; Csepany et al., 1990; Meyer Kate et al., 2012).

Owing to its dynamic and reversible nature, m6A RNA methylation is modulated by a multi-subunit complex of methyltransferase proteins known as "writers," which add methyl groups to the adenosine; demethylases known as "erasers," which aid in the removal of methyl groups; and RNA binding proteins known as "readers," which bind to methylated RNA and regulate discrete downstream mechanisms (Karthiya and Khandelia, 2020).

\section{Writers}

The methyltransferase complex is composed of several subunits with key methylases such as METTL3 and METTL14 and regulator proteins such as WTAP, METTL16, ZC3H13, and RBM15/15B (Karthiya and Khandelia, 2020). METTL3 and METTL14, which contain an S-adenosyl methionine (SAM) binding motif, form a core heterodimer and co-localize in nuclear speckles, with the former acting as an enzymatic component and the latter as an allosteric activator (Śledź and Jinek, 2016; Wang et al., 2016). The Wilms tumor 1 (WT1)-associated protein (WTAP), a splicing factor that modulates methylation, regulates the position of the heterodimer while indirectly increasing the catalytic capacity of methyltransferases (Ping et al., 2014; Zhang et al., 2019). RBM15/15B interacts with the methyltransferase complex with the aid of WTAP, further liaises with chromatin remodeling complexes, and modulates cortical development by recruiting the writer complex. ZC3H13 zinc finger protein, on the other hand, acts as a recruiter protein promoting localization of the writer complex in the nucleus. A relatively novel methyltransferase, METTL16, directs deposition of specific RNAs as well as U6 small nuclear RNA in addition to maintaining SAM homeostasis by adding methyl groups to the SAM synthase transcript, thereby gaining control of its stability and splicing mechanisms. Choosing a transcript for methylation is carried out by recruiting methyltransferases to specific promoters by certain transcription factors in addition to being influenced by histone 


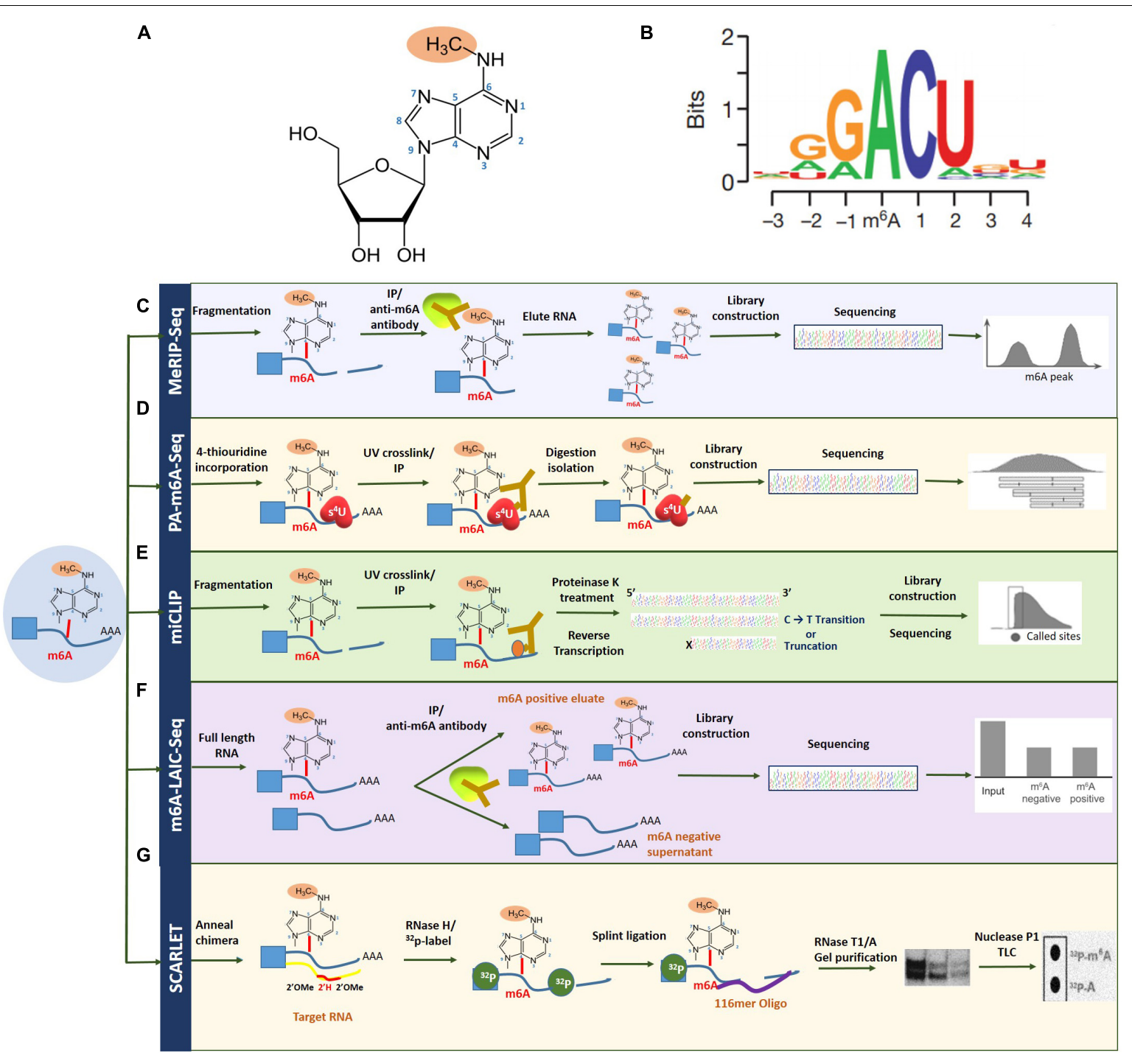

FIGURE 2 | Overview of m6A RNA methylation and m6A mapping technologies. (A) $N^{6}$-methyladenosine refers to the addition of a methyl group to the nitrogenous base present at the sixth position of the adenine residue in the RNA. (B) Topological analysis has indicated that m6A methylation occurs mainly near the $3^{\prime}$-UTR region, on adenosine residues presenting in a consensus motif of $R R m 6 A C H(R=G / A, H=A / C / U)$. Transcriptome-wide sequencing technologies for mapping m6A (C), MeRIP-seq (D), PA-m6A-seq (E), miCLIP (F), and m6A-LAIC-seq (G) SCARLET. Figure modified from Dominissini et al. (2012); Liu et al. (2013), and Li et al. (2016).

modifications such as H3K36me3 and H4K20me1 (KolasinskaZwierz et al., 2009; Tilgner et al., 2009; Zaccara et al., 2019).

\section{Erasers}

Eraser proteins function primarily by shaping the m6A landscape dynamically. RNA demethylases such as fat mass and obesity-associated protein (FTO; Jia et al., 2011) and AlkB family member 5 (ALKBH5; Zheng et al., 2013) belong to the ALKB family of dioxygenases that appear to have a restricted role under normal physiological conditions, with prominent functions in particular organs such as the testes and in certain ailments. Functionally, FTO performs an indirect role by sequentially oxidizing $N^{6}$ methyladenosine to $N^{6}$-formyladenosine, with an intermediate hydroxymethyladenosine, while ALKBH5 catalyzes direct removal of methylation (Chen and Wong, 2020).

\section{Readers}

The fate of mRNAs containing $\mathrm{m} 6 \mathrm{~A}$ is predominantly determined by different categories of m6A-binding proteins, termed "readers," such as YT521-B homology (YTH) domain family, heterogeneous nuclear ribonucleoproteins (hnRNPs), and IGF 2 mRNA-binding proteins (IGFBPs). Such proteins govern the m6A-related downstream cellular mechanisms in tumorigenesis, viral replication, adipogenesis, hemopoiesis, and immune regulation (Zhao et al., 2020).

The YTH domain-containing family (YTHDF) comprises YTHDF1, YTHDF2, YTHDF3, YTHDC1, and YTHDC2 
proteins that recognize $\mathrm{m} 6 \mathrm{~A}$ in a methylation-dependent manner. As the first cytoplasmic reader protein to be discovered, YTHDF2 performs the function of degrading methylated RNA by directly recruiting CCR4-NOT deadenylation complex to the target transcript, inherently reducing its stability and thereafter directing bound mRNA to relevant decay sites such as processing bodies (Wang et al., 2014; Du et al., 2016). YTHDF1 protein significantly augments mRNA translation efficiency through interactions with the translation initiation factor eIF3 and in some cases in an $\mathrm{m}^{7} \mathrm{G}$-cap-dependent manner (Wang et al., 2015; Liu et al., 2020a). YTHDC1 plays a pertinent role in exon selection during gene splicing (Roundtree and $\mathrm{He}, 2016$ ). YTHDC2 acts as a putative RNA helicase that governs RNA levels during cell meiosis by forming a complex with meiosis-specific coiled-coil domain-containing protein (MEIOC; Hsu et al., 2017; Jain et al., 2018).

Heterogeneous nuclear ribonucleoprotein protein family encompasses hnRNPs such as A2/B1 (HNRNPA2B1), C (HNRNPC), and G (HNRNPG), which have affinity to structural alterations induced by m6A methylation, commonly known as "m6A switch" (Liu et al., 2015, 2017; Wu et al., 2018). HNRNPA2B1 modulates alternative splicing of mRNA transcripts and processes primary miRNAs through DGCR8directed interactions (Alarcón et al., 2015). HNRNPC and HNRNPG impact pre-mRNA processing and pre-mRNA alternative splicing, respectively, via interactions with phosphorylated carboxy-terminal domain of enzyme RNA polymerase (Zarnack et al., 2013; Liu et al., 2017). The IGFBP family proteins use a $\mathrm{KH}$ RNA binding domain to identify m6A-containing transcripts and exert their function by actively recruiting RNA stabilizers such as $\mathrm{HuR}$ to protect mRNA transcripts from degradation (Chen and Wong, 2020).

\section{m6A Mapping Technologies}

The field of epitranscriptomics began gaining prominence with the development of methylated RNA immunoprecipitation/m6A sequencing (MeRIP/m6A-seq), capable of conducting a sitespecific analysis of $\mathrm{m} 6 \mathrm{~A}$ modification-based transcriptomic studies. This technique together with ChIP-seq depends on a specific m6A antibody to pull down m6A-containing transcripts that can subsequently be mapped by next-generation sequencing technologies (Zhang and Hamada, 2020). However, to circumvent issues with regard to identifying m6A-modified site, improved technologies such as photo-crosslinking-associated sequencing (PA-m6A-seq), which uses a photo-crosslinking method, and even single-nucleotide resolution m6A mapping are attainable (Linder et al., 2015). Furthermore, with additional UV crosslinking stratagems through techniques such as m6A individual-nucleotide-resolution crosslinking and immunoprecipitation (miCLIP), specific mutations and truncation profiles affected by the presence of m6A can be mapped precisely (Zhang et al., 2019).

Another contemporary technique for high-resolution m6A mapping is the site-specific cleavage and radioactive labeling followed by ligation-assisted extraction and thin-layer chromatography (SCARLET). As implicated by the name, the method involves site-specific cleavage and radiolabeling followed by splint ligation by DNA ligase, gel purification, and, finally, an analysis using thin-layer chromatography (Liu et al., 2013; Maity and Das, 2016). While this technique cannot employ highthroughput sequencing, newer methods such as m6A level and isoform characterization sequencing (m6A-LAIC-seq), which are compatible with high-throughput sequencing, have lately begun to see the limelight (Molinie et al., 2016). Also, since total RNA is ample without the requirement of enriching the targeted fraction of RNA, this method is deemed suitable for quantifying methylation levels in low abundance RNAs such as tRNAs (Linder et al., 2015). These m6A mapping technologies have been summarized in Figure 2. More recently, the third-generation single-nucleotide sequencing technologies such as Nanopore Direct Sequencing, capable of mapping RNA modifications at single base resolution, show promise in identifying m6A sites with improved accuracy (El-Serag and Rudolph, 2007; Fitzmaurice et al., 2019).

In recent years, several bioinformatics tools and databases addressing different purposes have been developed to organize and integrate complex datasets pertaining to m6A RNA modifications and its associated regulators. An interactive analysis of epitranscriptomic sequencing for m6A site identification can be performed by databases such as deepEA (Zhai et al., 2020) and iMRM (Liu and Chen, 2020), while RNAWRE (Nie et al., 2020), and M6A2Target (Deng et al., 2020) deposit m6A regulator datasets. Furthermore, comprehensive information on reliable m6A methylation sites and peaks from MeRIP-seq data are summarized in m6A-Atlas (Tang et al., 2020) and REPIC (Liu et al., 2020b), respectively. Bioinformatics resources such as RMDisease (Chen K. et al., 2020) and RMVar (Luo et al., 2020) can aid in better understanding the association between various epitranscriptomic modifications and their probable disease relevance.

\section{M6A RNA METHYLATION REGULATORS AND HALLMARKS OF HEPATOCELLULAR CARCINOMA}

The impact of m6A writers, readers, and erasers on key pathways that regulate the development of HCC are summarized in Figure 3 and Table 1.

\section{"Writers" in Hepatocellular Carcinoma Hallmarks}

In a recent study, Chen et al. (2018) identified suppressor of cytokine signaling 2 (SOCS2) as a downstream target of methyltransferase METTL3-induced m6A modification via the m6A reader protein YTHDF2-dependent pathway (Chen et al., 2018). Previous studies have investigated the function of SOCS2 as a cytokine-inducible negative regulator in Janus kinase/signal transduction and activation of the JAK/STAT pathway (Yoshikawa et al., 2001). SOCS2 downregulation is significantly correlated to advanced Tumor, Node, and Metastasis staging in addition to being a prognostic marker in HCC (Qiu et al., 2013). SOCS2 has also been associated with the 


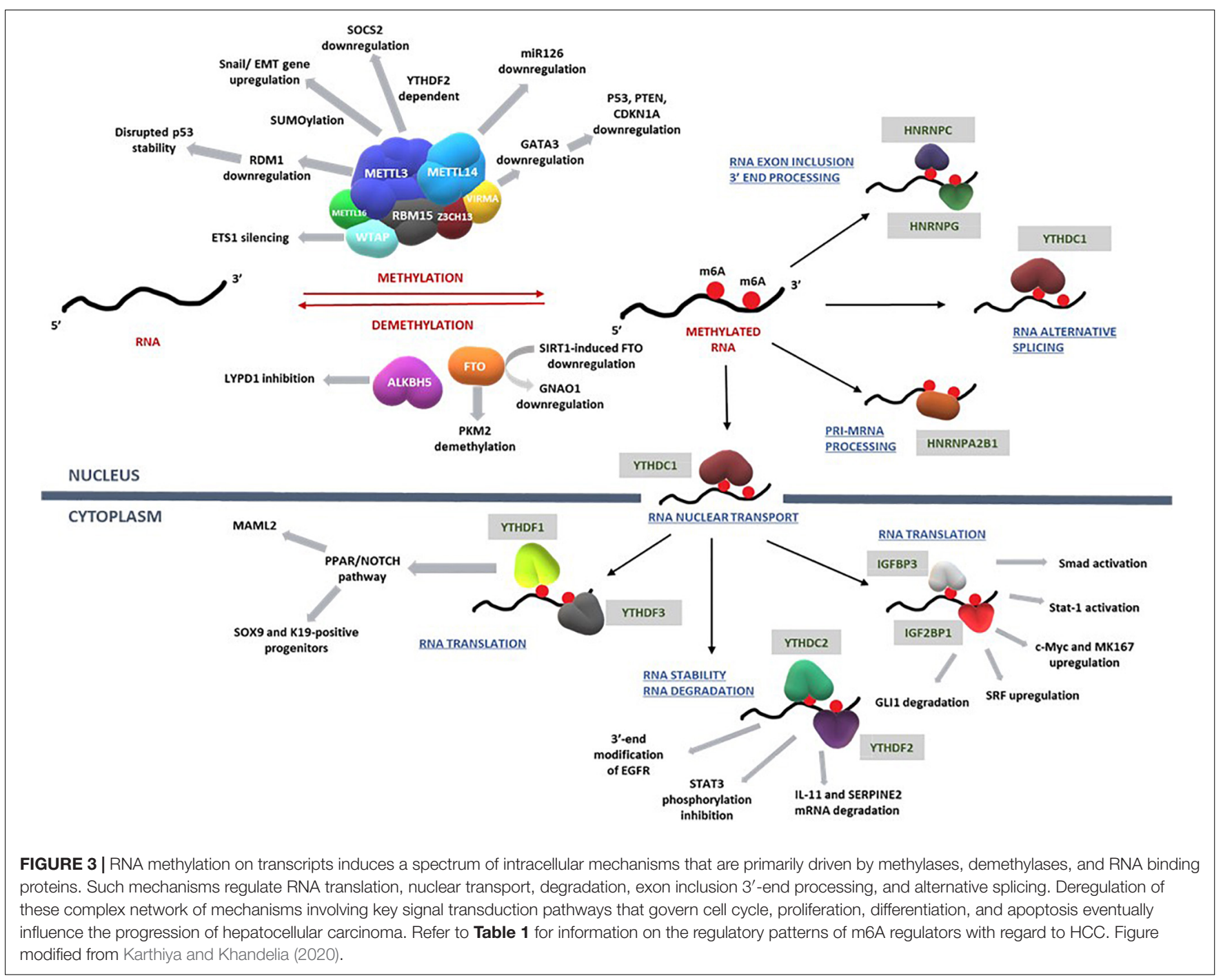

negative or positive regulation of GH, IGF-1, PRL, IL-2, IL-3, EPO, LIF, EGF, leptin, and IFN- $\alpha$-dependent signaling pathways, which are involved in tumorigenesis (Rico-Bautista et al., 2006). Another potential regulatory mechanism involves mitogenresponse SUMOylation of METTL3 that leads to upregulation of EMT genes, which inherently show a strong positive correlation to enhanced metastatic dissemination in HCC via m6A methyltransferase regulation of Snail, transcription factor, in mRNA homeostasis (Xu et al., 2020). Such mechanisms highlight the importance of $\mathrm{m} 6 \mathrm{~A}$-mediated methylation regulation, especially on EMT, as the latter promotes drug resistance, tumor recurrence, and metastasis, all of which contribute to HCC (Wang and Zhou, 2013).

Another study explored the m6A modification of RDM1 (RAD52 motif 1) mRNA induced by the overexpression of METTL3 in clinical HCC samples. The methyltransferase represses the expression of RDM1, which in turn mechanistically disrupts protein stability of tumor suppressors such as p53 protein and subsequent suppression of Raf and ERK phosphorylation, eventually promoting tumorigenesis in HCC
(Chen S. L. et al., 2019). Thus, such cascade of downstream processes leading to cancer could be solely traced back to the oncogenic behavior of METTL3.

Mechanistic studies revealed positive modulation of another subunit of methyltransferase, METTL14, on pri-miR126, a metastasis-inducing miRNA mechanism in a DGCR8-dependent manner (Ma et al., 2017). As a critical constituent of the canonical microprocessor complex for microRNA biogenesis, DGCR8 maintains the upregulation or deregulation of certain tumor-specific miRNAs that intrinsically contribute to enhanced cell proliferation, evasion of apoptosis via angiogenesis, and initiation of invasion and metastatic pathways, especially in HCC (Chu et al., 2014; Deng et al., 2019). Emerging evidence suggests that aberrantly downregulated miR126 boosted the poor overall survival associated with HCC (Bao et al., 2018). Restoring miR126 inhibited cell proliferation in HCC, arrested cell cycle advancement, and induced cell apoptosis (Zhao et al., 2015). Thus, the tumor-suppressive function of METTL14 could be a potential target in developing therapeutics targeting HCC. 
TABLE 1 | Role of m6A methylome in hepatocarcinogenesis.

\begin{tabular}{|c|c|c|c|c|}
\hline m6A regulator type & m6A regulator & Expression pattern & Function in hepatocellular carcinoma* & References \\
\hline Writer & METTL3 & Upregulated & $\begin{array}{l}\text { METTL3 suppresses SOCS2 expression through an } \\
\text { m6A-YTHDF2-dependent pathway. }\end{array}$ & $\begin{array}{l}\text { Chen et al., } \\
2018\end{array}$ \\
\hline Writer & METTL3 & Upregulated & $\begin{array}{l}\text { SUMOylation of METTL3 leads to upregulation of EMT } \\
\text { via m6A regulation of Snail transcription factor. }\end{array}$ & Xu et al., 2020 \\
\hline Writer & METTL3 & Upregulated & $\begin{array}{l}\text { METTL3 represses the expression of RDM1, which in } \\
\text { turn disrupts p53 protein stability. }\end{array}$ & $\begin{array}{l}\text { Chen S. L. } \\
\text { et al., } 2019\end{array}$ \\
\hline Writer & METTL14 & Downregulated & $\begin{array}{l}\text { METTL14 liaises with microprocessor protein DGCR8 } \\
\text { and positively modifies the microRNA } 126 \text { activity in an } \\
\text { m6A-dependent manner. }\end{array}$ & Ma et al., 2017 \\
\hline Writer & WTAP & Upregulated & $\begin{array}{l}\text { WTAP drives methylation of ETS1 leading to epigenetic } \\
\text { silencing of ETS1 via a HuR-dependent manner. }\end{array}$ & $\begin{array}{l}\text { Chen Y. et al., } \\
2019\end{array}$ \\
\hline Writer & KIAA1429 & Upregulated & $\begin{array}{l}\text { KIAA1429, with the aid of GATA3-AS, methylates } \\
\text { GATA3 pre-mRNA, separating HuR and degrading } \\
\text { GATA3 pre-mRNA. }\end{array}$ & Lan et al., 2019 \\
\hline Eraser & FTO & Upregulated & $\begin{array}{l}\text { FTO mechanistically triggers demethylation of PKM2 } \\
\text { mRNA and enhances PKM2 translated. }\end{array}$ & Li et al., 2019 \\
\hline Eraser & FTO & Downregulated & $\begin{array}{l}\text { Oncogenic protein SIRT1 downregulates FTO by } \\
\text { activating RANBP2 leading to overexpression of } \\
\text { m6A + GNAO1. }\end{array}$ & $\begin{array}{l}\text { Liu et al., } \\
\text { 2020c }\end{array}$ \\
\hline Eraser & ALKBH5 & Downregulated & $\begin{array}{l}\text { ALKBH5 modulates post-transcriptional inhibition of } \\
\text { LY6/PLAUR domain-containing } 1 \text { (LYPD1), which in turn } \\
\text { is stabilized by m6A reader IGF2BP1. }\end{array}$ & $\begin{array}{l}\text { Chen Y. et al., } \\
2020\end{array}$ \\
\hline Reader & YTHDF1 & Upregulated & Modulates PPAR/NOTCH signaling pathways. & $\begin{array}{l}\text { Zhao et al., } \\
\qquad 2018\end{array}$ \\
\hline Reader & YTHDF2 & Downregulated & $\begin{array}{l}\text { YTHDF2 binds to EGFR } 3^{\prime} \text {-UTR promoting degradation } \\
\text { of EGFR mRNA. }\end{array}$ & $\begin{array}{l}\text { Zhong et al., } \\
\qquad 2019\end{array}$ \\
\hline Reader & YTHDF2 & Downregulated & $\begin{array}{l}\text { Repressed YTHDF2 activity disrupts tumor vasculature } \\
\text { suppression that drives IL11 and SERPINE2 mRNA } \\
\text { decay. }\end{array}$ & $\begin{array}{l}\text { Hou et al., } \\
2019\end{array}$ \\
\hline Reader & IGFBP3 & Downregulated & $\begin{array}{l}\text { IGFBP-3 regulates growth suppression signals via } \\
\text { altering TGF- } \beta \text { and/or Rb pathways. }\end{array}$ & $\begin{array}{l}\text { Yumoto et al., } \\
2005\end{array}$ \\
\hline Reader & IGF2BP1 & Upregulated & $\begin{array}{l}\text { IGF2BP1 stabilizes c-MYC and MKI67 mRNAs and } \\
\text { enhances c-Myc and Ki-67 protein translation. }\end{array}$ & $\begin{array}{l}\text { Gutschner } \\
\text { et al., } 2014\end{array}$ \\
\hline Reader & IGF2BP1 & Downregulated & $\begin{array}{l}\text { LINC01093 directly binds IGF2BP1, disrupting } \\
\text { interactions between IGF2BP1 and GLI1 mRNA leading } \\
\text { to the mRNA degradation of the latter. }\end{array}$ & He et al., 2019 \\
\hline
\end{tabular}

*Based on in vitro and in vivo studies involving patient samples and hepatocellular carcinoma (HCC) cell lines.

Wilms tumor associated protein, another subunit of the methyltransferase complex that localizes in nuclear speckles, is highly expressed in HCC and serves as an independent predictor of hepatocarcinogenesis (Ping et al., 2014; Chen Y. et al., 2019). WTAP has been shown to promote proliferation and tumorigenesis by epigenetically silencing the ETS1 transcription factor (Chen Y. et al., 2019). Accumulating evidence suggests that ETS proteins regulate various aspects of cancer hallmarks such as proliferation inducing cell signaling, promoting angiogenesis, and evading apoptosis through enhanced nuclear transport (Myers et al., 2005), recruitment of co-repressors (Okamura et al., 2009), increased DNA binding of nuclear proteins (Sharrocks, 2001), and transactivation of certain genes such as VEGF (Tetsu and McCormick, 2017; Fry and Inoue, 2018). For example, ETS1 exhibits preferential binding to wild-type p53, suggesting tumor-suppressive functions in various cancers (Martinez, 2016). ETS1 was also shown to directly upregulate genes necessary for angiogenesis and extracellular matrix remodeling, such as the matrix metalloproteinases MMP-1, MMP-3, and MMP-9 and integrin $\beta 3$ (Oda et al., 1999). Thus, WTAP-mediated epigenetic silencing of ETS1 could indicate a cogent m6A regulator-driven tumorigenesis mechanism at play.

KIAA1429, another crucial component of the m6A methyltransferase complex, is upregulated in HCC cells exhibiting poor prognosis (Lan et al., 2019). Furthermore, based on extensive in vitro and in vivo studies, they identified GATA binding protein 3 (GATA3) as a direct downstream target of KIAA1429-induced m6A modifications. GATA3 is a transcription factor composed of two zinc fingers at the carboxyl terminus, which has been linked with suppression of metastasis, tumor microenvironment modulation, and promotion of cellular differentiation (Zheng and Blobel, 2010; Chou et al., 2013; Siddiqui et al., 2014). KIAA1429, under the guidance of the long non-coding RNA (lncRNA) GATA3-AS, facilitates m6A methylation on the $3^{\prime}$-UTR of GATA3 pre-mRNA, disrupting the activity of the RNA binding protein HuR to GATA3 premRNA, eventually downregulating GATA3 mRNA expression (Lan et al., 2019). GATA3 targets one of the classical hallmarks 
of cancer, the capability of tumor cells to induce invasion and metastasis (Hanahan and Weinberg, 2000; Chou et al., 2010). In fact, a previous study showed that GATA3-AS drives hepatocarcinogenesis via metastasis, particularly in HCC, by suppressing tumor suppressor genes such as p53, PTEN, and key inhibitors, namely, CDKN1A (Luo et al., 2019).

\section{"Erasers" in Hepatocellular Carcinoma Hallmarks}

Fat mass and obesity-associated protein demethylase is significantly upregulated in HCC correlating with poor prognosis, while triggering demethylation of pyruvate kinase 2 (PKM2) mRNA (Li et al., 2019). PKM2, a rate-limiting glycolytic muscle isozyme, acts as a catalysis mediator in the irreversible transphosphorylation between adenosine diphosphate and phosphoenolpyruvate, leading to production of pyruvate and ATP (Altenberg and Greulich, 2004). In neoplastic cells, PKM2 is overexpressed under the regulation of oncoproteins such as c-Myc, which activates transcription of hnRNPs, a class of reader proteins that in turn control mRNA m6A regulation (David et al., 2010; Liu et al., 2015). PKM2 thus prompts metabolic reprogramming, a core hallmark of cancer, by facilitating anabolic metabolism in proliferating cells (Ward and Thompson, 2012). Another study that scrutinized the clinicopathological features in HCC patients with high PKM2 levels observed poor prognosis coupled with lower creatinine levels, advanced stage, and higher grade in such groups (Lu et al., 2018). Although Gene Expression Profiling Interactive Analysis (GEPIA) and The Cancer Genome Atlas (TCGA) databases show a strong correlation between the mRNA expression levels of FTO and PKM2, the exact dynamics of $\mathrm{m} 6 \mathrm{~A}$ demethylases and tumorigenesis inducing altered metabolism portrays a research gap that is yet to be filled.

Sirtuin 1 (SIRT1), also known as NAD-dependent deacetylase SIRT1, is frequently upregulated in HCC, where it regulates chemoresistance and metastasis while maintaining tumorigenicity and self-renewal capabilities of liver cancer stem cells (Wilking and Ahmad, 2015; Farcas et al., 2019). SIRT1 also upregulates oncogenes such as $\beta$-catenin (Firestein et al., 2008), HIF-1 $\alpha$ (Laemmle et al., 2012), and c-Myc (Jang et al., 2012), especially in liver cancers. Functioning as an oncogene, SIRT1 downregulates m6A demethylase, FTO, by activating nucleoporin $\mathrm{RaBnP} 2$, a protein with a small ubiquitin-related modifier (SUMO) E3 ligase activity. RaBnP2 triggers SUMOylation of FTO at lysine (K)-216 site leading to FTO degradation (Liu et al., 2020c). Furthermore, guanine nucleotide-binding protein $\mathrm{G}$ (o) subunit alpha (GNAO1), a tumor suppressor, is an m6A-mediated downstream target of FTO. SIRT1 induces downregulation of FTO, thus leading to degradation of GNAO1, which in turn fuels hepatocarcinogenesis (Liu et al., 2020c).

AlkB family member 5 demethylase is downregulated in HCC with the functional role of suppressing proliferation and invasion capabilities of tumor cells (Chen Y. et al., 2020). Mechanistically, however, ALKBH5-regulated demethylation leads to posttranscriptional inhibition of LY6/PLAUR domain-containing 1
(LYPD1), a neurotransmitter receptor-binding protein involved in the regulation of breast and ovarian cancers, with the potential to act as a prognostic marker (Wang N. et al., 2019). Given that, in general, healthy tissues express relatively low levels of LYPD1 than most peripheral organs (Egerod et al., 2007), downregulation of ALKBH5 leads to significant upregulation of LYPD1, an established oncogenic driver of HCC (Chen Y. et al., 2020). While Chen et al. concluded that an explicit link between LYPD1 and cancer signaling pathways is yet to be established, they were able to provide evidence of the involvement of ALKBH5 in the regulation of P13K/AKT/mTOR and GTPase pathways, major hallmarks of cancer, through gene ontology and ALKBH5/LYPD1 gene knockdown studies (Etienne-Manneville and Hall, 2002; Manning and Toker, 2017; Chen Y. et al., 2020). Potential involvement of ALKBH5/LYPD1-mediated modulation could therefore explain the poor prognosis of HCC.

\section{"Readers" in Hepatocellular Carcinoma Hallmarks}

YTH domain-containing family $1 \mathrm{~m} 6 \mathrm{~A}$ reader protein is significantly upregulated in HCC. Based on gene ontology and Kyoto Encyclopedia of Genes and Genomes (KEGG) pathway analyses, YTHDF1 was found to be associated with p53, NOTCH, and peroxisome proliferator-activated receptors (PPAR) signaling pathways, which are known to aid in HCC progression (Han et al., 2019). PPAR Beta/Delta, ligandactivated transcription factors, have been known to favor pro-tumorigenicity while being central in the interplay of different cancer hallmark capabilities, such as cell proliferation, immune function, induction of angiogenesis, and senescence and replicative immortality (Wagner and Wagner, 2020). For example, in HCC cells, PPAR $\gamma$ activation leads to cell growth inhibition by overexpression of cell cycle arrest-inducing proteins such as cdc2, p21, p27, and CITED2, in addition to downregulation of cyclin D1, a protein that promotes cell cycle (Hsu and Chi, 2014). Contrarily, oxidative stress imposed by peroxisome proliferators and subsequent induction of PPAR $\alpha$ enables hepatocellular proliferation while inhibiting apoptosis (Reddy et al., 1976; Tachibana et al., 2008). The NOTCH cell fate-regulatory pathway, another probable downstream target of YTHDF1, too, has been shown to be pro-oncogenic, due to its associations with NOTCH coactivator MAML2, a target of genetic alterations, and activation of Sox9- and K19-positive progenitors leading to liver tumorigenesis (Nalesnik et al., 2012; Strazzabosco and Fabris, 2012; Morell and Strazzabosco, 2014). Thus, the relationship between PPAR/NOTCH signaling pathways and the epitranscriptomic role of YTHDF1 is an area that warrants further research.

YTH domain-containing family2 is a novel regulator of tumor-promoting inflammation (Hou et al., 2019), which binds to m6A-containing RNAs and directs them to decay sites for degradation, thereby contributing toward regulating mRNA stability (Du et al., 2016). YTHDF2 inhibits STAT3 phosphorylation and tumorigenesis through interleukin 11 (IL11) mRNA degradation, which encodes IL-6 family cytokine that triggers HCC with potential for proliferation and metastasis. 
The complex role of IL-11 as a pro-inflammatory cytokine in regulating immune response through activation of the JAKSTAT3 signaling pathway, in turn, provides the pro-inflammatory microenvironment required for malignant transformation and tumor progression (Bollrath et al., 2009; Kortylewski et al., 2009). In fact, another recent publication showed that IL-11 levels were significant in postsurgical HCC recurrence due to the associated enhancement of the IL-11-STAT3 signaling (Wang D. et al., 2019). Furthermore, YTHDF2 targets the mRNA degradation of serpin family E member 2 (SERPINE2), a protein present in the extracellular matrix and known to contribute to tumor invasion and metastasis through the oncogenic activation of BRAF, RAS, and MEK, which in turn influence the proneoplastic mechanisms of extracellular signal-regulated kinase (ERK) signaling (Bergeron et al., 2010; Yang et al., 2018).

YTH domain-containing family2 represses cell proliferation and activation of MEK and ERK in HCC cells through modification of $3^{\prime}$-UTR site of EGFR, a key factor in epithelial malignancies and directing the subsequent degradation of EGFR mRNA (Zhong et al., 2019). The integrative effects of an enhanced TGF- $\alpha$-EGFR-MAPK activity on driving neoplasticity in HCC cells (Baek et al., 2010), coupled with a range of cancer hallmarks that EGFR influences, could potentially be negated by the upregulation of m6A regulator YTHDF2.

IGF 2 mRNA-binding protein3 is regarded as a putative tumor suppressor as well as mediator of mechanisms involving growth suppression. Yumoto et al. (2005) postulated that IGFBP3 expression in HCC was concomitant with abnormalities in the TGF- $\beta$ receptor and/or effectors of its downstream signaling pathway such as Rb (Yumoto et al., 2005). It has been shown that IGFBP3 binds to its putative receptor IGFBP-3R inducing apoptosis, as well as binds to TGF- $\beta$ receptor, eventually causing Smad activation and thereby inducing apoptosis. This reader protein also activates Stat-1 transcription factor and binds to nuclear receptors like $\mathrm{RXR}-\alpha$, prompting anti-apoptotic and anti-proliferative effects (Zappala et al., 2008; Shahjee and Bhattacharyya, 2014).

IGF 2 mRNA-binding proteins1 is strongly upregulated in HCC, and it stabilizes and upregulates c-Myc and MK167, two major regulators of cell proliferation and apoptosis (Gutschner et al., 2014). This oncofetal reader protein also promotes the expression of serum response factor (SRF), a critical transcription factor that regulates cell adhesion, cytoskeletal regulation, and cell migration, via m6A-mediated impairment of SRF mRNA decay (Descot et al., 2009; Leitner et al., 2011; Esnault et al., 2014). At the post-transcriptional level, IGF2BP1 controls the expression of PDLIM7 and FOXK1, two genes known to promote HCC hallmarks such as tumor proliferation and metastasis (Müller et al., 2019). Recently, another study showed that liver-specific lncRNAs directly bind IGF2BP1, enabling mRNA degradation of transcription factor glioma-associated oncogene homolog 1 (GLI1) mRNA, the latter known to be associated with the hepatocarcinogenesis-inducing Hedgehog pathway (Della Corte et al., 2017; He et al., 2019). Another contemporary work revealed that IGF2BP1 stabilizes the transcript of LINC01138, an oncogenic long intergenic noncoding RNA that promotes tumorigenesis and tumor invasion
(Li et al., 2018). Thus, it can be postulated that IGF2BP1 reader proteins are involved in a variety of complex downstream mechanisms that remarkably influence metastasis hallmark of hepatocarcinogenesis, especially HCC.

\section{CONCLUSION AND FUTURE PERSPECTIVES}

In recent years, immense integrative and comprehensive genomic and molecular analyses exploring potential diagnostic and prognostic targets for HCC have brought to light several prominent therapeutic solutions to curb the burden of HCC. While the role of genetic and epigenetic mechanisms on the pathogenesis of hepatocarcinogenesis has been the subject of extensive research, the network of mechanisms that governs epitranscriptomics and its associated RNA modifications, much less its association with liver tumorigenesis, is an emerging field that warrants further investigation. While the field of epitranscriptomics has witnessed a rapid upsurge in research publications in the recent decade, the mechanistic and functional aspects of $\mathrm{m} 6 \mathrm{~A}$ regulators and methylation levels in hepatocarcinogenesis, particularly HCC, still remains ambiguous, metaphorically signified by the parable of the "blind men and the elephant." We are yet to find cogent answers to prevailing questions such as the following: How does m6A methylation affect the gene expression regulations in liver tumorigenesis? Which interwoven regulatory networks of pathways contribute toward m6A methylation and the expression of $\mathrm{m} 6 \mathrm{~A}$ regulator proteins? What $\mathrm{m} 6 \mathrm{~A}$-associated mechanistic pathways are modified by external factors such as hepatitis $\mathrm{B}$ and $\mathrm{C}$, aflatoxin exposure, and other causal factors of HCC? Do m6A regulators function as oncogenes or tumor suppressors? Only upon identifying the major cancer hallmark influencers of epitranscriptomic regulation can we successfully design therapeutic targets to combat HCC.

\section{AUTHOR CONTRIBUTIONS}

ES contributed to manuscript writing, figure preparation, and final editing. NB contributed to critically revising the article and rectifying grammatical errors. $\mathrm{ZL}$, JM, and RR contributed to this manuscript with conception and revision.

\section{FUNDING}

This work was supported by the Key Program Special Fund of Xi'an Jiaotong-Liverpool University (KSF-E-23 to RR) and the Research Development Fund of Xi'an Jiaotong-Liverpool University (RDF-17-02-31 to RR).

\section{ACKNOWLEDGMENTS}

We apologize to the authors whose excellent works have not been quoted in this review manuscript due to space restriction. 


\section{REFERENCES}

Adams, J. M., and Cory, S. (2007). The Bcl-2 apoptotic switch in cancer development and therapy. Oncogene 26, 1324-1337. doi: 10.1038/sj.onc. 1210220

Alarcón, C., Goodarzi, H., Lee, H., Liu, X., Tavazoie, S., and Tavazoie, S. (2015). HNRNPA2B1 is a mediator of $\mathrm{m} 6 \mathrm{~A}$-dependent nuclear RNA processing events. Cell 162, 1299-1308. doi: 10.1016/j.cell.2015.08.011

Alqahtani, A., Khan, Z., Alloghbi, A., Said Ahmed, T. S., Ashraf, M., and Hammouda, D. M. (2019). Hepatocellular carcinoma: molecular mechanisms and targeted therapies. Medicina (Kaunas) 55:526.

Altenberg, B., and Greulich, K. O. (2004). Genes of glycolysis are ubiquitously overexpressed in 24 cancer classes. Genomics 84, 1014-1020. doi: 10.1016/j. ygeno.2004.08.010

Baek, J. Y., Morris, S. M., Campbell, J., Fausto, N., Yeh, M. M., and Grady, W. M. (2010). TGF-beta inactivation and TGF-alpha overexpression cooperate in an in vivo mouse model to induce hepatocellular carcinoma that recapitulates molecular features of human liver cancer. Int. J. Cancer 127, 1060-1071. doi: $10.1002 /$ ijc. 25127

Bao, J., Yu, Y., Chen, J., He, Y., Chen, X., Ren, Z., et al. (2018). MiR-126 negatively regulates PLK-4 to impact the development of hepatocellular carcinoma via ATR/CHEK1 pathway. Cell Death Dis. 9:1045.

Bergeron, S., Lemieux, E., Durand, V., Cagnol, S., Carrier, J. C., Lussier, J. G., et al. (2010). The serine protease inhibitor serpinE2 is a novel target of ERK signaling involved in human colorectal tumorigenesis. Mol. Cancer 9:271. doi: 10.1186/1476-4598-9-271

Beudeker, B. J. B., and Boonstra, A. (2020). Circulating biomarkers for early detection of hepatocellular carcinoma. Ther. Adv. Gastroenterol. 13, 1-11.

Biselli-Chicote, P. M., Oliveira, A. R., Pavarino, E. C., and Goloni-Bertollo, E. M. (2012). VEGF gene alternative splicing: pro- and anti-angiogenic isoforms in cancer. J. Cancer Res. Clin. Oncol. 138, 363-370. doi: 10.1007/s00432-0111073-2

Bollrath, J., Phesse, T. J., von Burstin, V. A., Putoczki, T., Bennecke, M., Bateman, T., et al. (2009). gp130-Mediated Stat3 activation in enterocytes regulates cell survival and cell-cycle progression during colitis-associated tumorigenesis. Cancer Cell 15, 91-102. doi: 10.1016/j.ccr.2009.01.002

Bosch, F. X., Ribes, J., Díaz, M., and Cléries, R. (2004). Primary liver cancer: worldwide incidence and trends. Gastroenterology 127(5 Suppl. 1), S5-S16.

Campbell, J. S., Hughes, S. D., Gilbertson, D. G., Palmer, T. E., Holdren, M. S., Haran, A. C., et al. (2005). Platelet-derived growth factor C induces liver fibrosis, steatosis, and hepatocellular carcinoma. Proc. Natl. Acad. Sci. U.S.A. 102, 3389-3394. doi: 10.1073/pnas.0409722102

Chen, K., Song, B., Tang, Y., Wei, Z., Xu, Q., Su, J., et al. (2020). RMDisease: a database of genetic variants that affect RNA modifications, with implications for epitranscriptome pathogenesis. Nucleic Acids Res. 49, D1396-D1404.

Chen, M., Wei, L., Law, C. T., Tsang, F. H., Shen, J., Cheng, C. L., et al. (2018). RNA N6-methyladenosine methyltransferase-like 3 promotes liver cancer progression through YTHDF2-dependent posttranscriptional silencing of SOCS2. Hepatology (Baltimore, Md) 67, 2254-2270. doi: 10.1002/hep.29683

Chen, M., and Wong, C.-M. (2020). The emerging roles of N6methyladenosine (m6A) deregulation in liver carcinogenesis. Mol. Cancer 19:44.

Chen, S.-L., Liu, L. L., Wang, C., Lu, S. X., Yang, X., He, Y., et al. (2019). Loss of RDM1 enhances hepatocellular carcinoma progression via p53 and Ras/Raf/ERK pathways. Mol. Oncol. 14, 373-386. doi: 10.1002/1878-0261. 12593

Chen, Y., Peng, C., Chen, J., Chen, D., Yang, B., He, B., et al. (2019). WTAP facilitates progression of hepatocellular carcinoma via m6A-HuR-dependent epigenetic silencing of ETS1. Mol. Cancer 18:127.

Chen, Y., Zhao, Y., Chen, J., Peng, C., Zhang, Y., Tong, R., et al. (2020). ALKBH5 suppresses malignancy of hepatocellular carcinoma via m(6)A-guided epigenetic inhibition of LYPD1. Mol. Cancer 19:123.

Chou, J., Lin, J. H., Brenot, A., Kim, J. W., Provot, S., and Werb, Z. (2013). GATA3 suppresses metastasis and modulates the tumour microenvironment by regulating microRNA-29b expression. Nat. cell Biol. 15, 201-213. doi: 10.1038/ ncb2672

Chou, J., Provot, S., and Werb, Z. (2010). GATA3 in development and cancer differentiation: cells GATA have it! J. Cell. Physiol. 222, 42-49. doi: 10.1002/ jcp. 21943
Chu, R., Mo, G., Duan, Z., Huang, M., Chang, J., Li, X., et al. (2014). miRNAs affect the development of hepatocellular carcinoma via dysregulation of their biogenesis and expression. Cell Commun. Signal. 12:45.

Csepany, T., Lin, A., Baldick, C., and Beemon, K. (1990). Sequence specificity of mRNA N6-adenosine methyltransferase. J. Biol. Chem. 265, 20117-20122. doi: 10.1016/s0021-9258(17)30477-5

David, C. J., Chen, M., Assanah, M., Canoll, P., and Manley, J. L. (2010). HnRNP proteins controlled by c-Myc deregulate pyruvate kinase mRNA splicing in cancer. Nature 463, 364-368. doi: 10.1038/nature08697

Della Corte, C. M., Viscardi, G., Papaccio, F., Esposito, G., Martini, G., Ciardiello, D., et al. (2017). Implication of the hedgehog pathway in hepatocellular carcinoma. World J. Gastroenterol. 23, 4330-4340. doi: 10.3748/wjg.v23.i24. 4330

DeNardo, D. G., Andreu, P., and Coussens, L. M. (2010). Interactions between lymphocytes and myeloid cells regulate pro- versus anti-tumor immunity. Cancer Metastasis Rev. 29, 309-316. doi: 10.1007/s10555-010-9223-6

Deng, L., Ren, R., Liu, Z., Song, M., Li, J., Wu, Z., et al. (2019). Stabilizing heterochromatin by DGCR8 alleviates senescence and osteoarthritis. Nat. Commun. 10:3329.

Deng, S., Zhang, H., Zhu, K., Li, X., Ye, Y., Li, R., et al. (2020). M6A2Target: a comprehensive database for targets of $\mathrm{m} 6 \mathrm{~A}$ writers, erasers and readers. Brief. Bioinform. 1-11.

Descot, A., Hoffmann, R., Shaposhnikov, D., Reschke, M., Ullrich, A., and Posern, G. (2009). Negative regulation of the EGFR-MAPK cascade by actin-MALmediated Mig6/Errfi-1 induction. Mol. Cell 35, 291-304. doi: 10.1016/j.molcel. 2009.07.015

Desrosiers, R., Friderici, K., and Rottman, F. (1974). Identification of methylated nucleosides in messenger RNA from Novikoff hepatoma cells. Proc. Natl. Acad. Sci. U.S.A. 71, 3971-3975. doi: 10.1073/pnas.71.10.3971

Dominissini, D., Moshitch-Moshkovitz, S., Schwartz, S., Salmon-Divon, M., Ungar, L., Osenberg, S., et al. (2012). Topology of the human and mouse m6A RNA methylomes revealed by m6A-seq. Nature 485, 201-206. doi: 10.1038/ nature 11112

Donaires, F. S., Scatena, N. F., Alves-Paiva, R. M., Podlevsky, J. D., Logeswaran, D., Santana, B. A., et al. (2017). Telomere biology and telomerase mutations in cirrhotic patients with hepatocellular carcinoma. PLoS One 12:e183287. doi: 10.1371/journal.pone.0183287

Du, H., Zhao, Y., He, J., Zhang, Y., Xi, H., Liu, M., et al. (2016). YTHDF2 destabilizes m6A-containing RNA through direct recruitment of the CCR4NOT deadenylase complex. Nat. Commun. 7:12626.

Egeblad, M., Nakasone, E. S., and Werb, Z. (2010). Tumors as organs: complex tissues that interface with the entire organism. Dev. Cell 18, 884-901. doi: 10.1016/j.devcel.2010.05.012

Egerod, K., Holst, B., Petersen, P., Hansen, J., Mulder, J., Hokfelt, T., et al. (2007). GPR39 splice variants versus antisense gene LYPD1: expression and regulation in gastrointestinal tract, endocrine pancreas, liver, and white adipose tissue. Mol. Endocrinol. 21, 1685-1698. doi: 10.1210/me.2007-0055

El-Serag, H. B., and Rudolph, K. L. (2007). Hepatocellular carcinoma: epidemiology and molecular carcinogenesis. Gastroenterology 132, 2557-2576. doi: 10.1053/ j.gastro.2007.04.061

Enguita-Germán, M., and Fortes, P. (2014). Targeting the insulin-like growth factor pathway in hepatocellular carcinoma. World J. Hepatol. 6, 716-737. doi: 10. 4254/wjh.v6.i10.716

Esnault, C., Stewart, A., Gualdrini, F., East, P., Horswell, S., Matthews, N., et al. (2014). Rho-actin signaling to the MRTF coactivators dominates the immediate transcriptional response to serum in fibroblasts. Genes Dev. 28, 943-958. doi: $10.1101 /$ gad.239327.114

Etienne-Manneville, S., and Hall, A. (2002). Rho GTPases in cell biology. Nature 420, 629-635.

Farazi, P. A., Glickman, J., Horner, J., and Depinho, R. A. (2006). Cooperative interactions of p53 mutation, telomere dysfunction, and chronic liver damage in hepatocellular carcinoma progression. Cancer Res. 66, 4766-4773. doi: 10. 1158/0008-5472.can-05-4608

Farcas, M., Gavrea, A.-A., Gulei, D., Ionescu, C., Irimie, A., Catana, C. S., et al. (2019). SIRT1 in the development and treatment of hepatocellular carcinoma. Front. Nutr. 6:148. doi: 10.3389/fnut.2019.00148

Ferlay, J., Shin, H. R., Bray, F., Forman, D., Mathers, C., and Parkin, D. M. (2010). Estimates of worldwide burden of cancer in 2008: GLOBOCAN 2008. Int. J. Cancer 127, 2893-2917. doi: 10.1002/ijc.25516 
Firestein, R., Blander, G., Michan, S., Oberdoerffer, P., Ogino, S., Campbell, J., et al. (2008). The SIRT1 deacetylase suppresses intestinal tumorigenesis and colon cancer growth. PLoS One 3:e2020. doi: 10.1371/journal.pone.0002020

Fitzmaurice, C., Abate, D., Abbasi, N., Abbastabar, H., Abd-Allah, F., AbdelRahman, O., et al. (2019). Global, regional, and national cancer incidence, mortality, years of life lost, years lived with disability, and disability-adjusted life-years for 29 Cancer Groups, 1990 to 2017: a systematic analysis for the Global Burden of Disease Study. JAMA Oncol. 5, 1749-1768.

Fry, E. A., and Inoue, K. (2018). Aberrant expression of ETS1 and ETS2 proteins in cancer. Cancer Rep. Rev. 2.

Gutschner, T., Hämmerle, M., Pazaitis, N., Bley, N., Fiskin, E., Uckelmann, H., et al. (2014). Insulin-like growth factor 2 mRNA-binding protein 1 (IGF2BP1) is an important protumorigenic factor in hepatocellular carcinoma. Hepatology 59, 1900-1911. doi: 10.1002/hep.26997

Hamdy, M., Shaheen, K., Awad, M., Barakat, E., Shalaby, S., Gupta, N., et al. (2020). Vascular endothelial growth factor (VEGF) as a biochem- ical marker for the diagnosis of hepatocellular carcinoma (HCC). Clin. Pract. 17, 1441-1453.

Han, D., Liu, J., Chen, C., Dong, L., Liu, Y., Chang, R., et al. (2019). Antitumour immunity controlled through mRNA m6A methylation and YTHDF1 in dendritic cells. Nature 566, 270-274. doi: 10.1038/s41586-019-0916-x

Hanahan, D., and Weinberg, R. A. (2000). The hallmarks of cancer. Cell 100, $57-70$.

Hanahan, D., and Weinberg, R. A. (2011). Hallmarks of cancer: the next generation. Cell 144, 646-674. doi: 10.1016/j.cell.2011.02.013

He, J., Zuo, Q., Hu, B., Jin, H., Wang, C., Cheng, Z., et al. (2019). A novel, liver-specific long noncoding RNA LINC01093 suppresses HCC progression by interaction with IGF2BP1 to facilitate decay of GLI1 mRNA. Cancer Lett. 450, 98-109. doi: 10.1016/j.canlet.2019.02.033

Hou, J., Zhang, H., Liu, J., Zhao, Z., Wang, J., Lu, Z., et al. (2019). YTHDF2 reduction fuels inflammation and vascular abnormalization in hepatocellular carcinoma. Mol. Cancer 18:163.

Hsu, H.-T., and Chi, C.-W. (2014). Emerging role of the peroxisome proliferatoractivated receptor-gamma in hepatocellular carcinoma. J. Hepatocell. Carcinoma 1, 127-135. doi: 10.2147/jhc.s48512

Hsu, P. J., Zhu, Y., Ma, H., Guo, Y., Shi, X., Liu, Y., et al. (2017). Ythdc2 is an N(6)methyladenosine binding protein that regulates mammalian spermatogenesis. Cell Res. 27, 1115-1127. doi: 10.1038/cr.2017.99

Hugo, H., Ackland, M. L., Blick, T., Lawrence, M. G., Clements, J. A., Williams, E. D., et al. (2007). Epithelial-mesenchymal and mesenchymal-epithelial transitions in carcinoma progression. J. Cell. Physiol. 213, 374-383. doi: 10. $1002 /$ jcp. 21223

Jackson, S. P., and Bartek, J. (2009). The DNA-damage response in human biology and disease. Nature. 461, 1071-1078. doi: 10.1038/nature08467

Jain, D., Puno, M. R., Meydan, C., Lailler, N., Mason, C. E., Lima, C. D., et al. (2018). ketu mutant mice uncover an essential meiotic function for the ancient RNA helicase YTHDC2. Elife 7:e30919.

Jang, K. Y., Noh, S. J., Lehwald, N., Tao, G.-Z., Bellovin, D. I., Park, H. S., et al. (2012). SIRT1 and c-Myc promote liver tumor cell survival and predict poor survival of human hepatocellular carcinomas. PLoS One 7:e45119. doi: 10.1371/ journal.pone.0045119

Jia, G., Fu, Y., Zhao, X., Dai, Q., Zheng, G., Yang, Y., et al. (2011). N6Methyladenosine in nuclear RNA is a major substrate of the obesity-associated FTO. Nat. Chem. Biol. 7, 885-887. doi: 10.1038/nchembio.687

Karthiya, R., and Khandelia, P. (2020). m6A RNA methylation: ramifications for gene expression and human health. Mol. Biotechnol. 62, 467-484. doi: 10.1007/ s12033-020-00269-5

Kedmi, M., Ben-Chetrit, N., Körner, C., Mancini, M., Ben-Moshe, N. B., Lauriola, M., et al. (2015). EGF induces microRNAs that target suppressors of cell migration: miR-15b targets MTSS1 in breast cancer. Sci. Signal. 8:ra29. doi: 10.1126/scisignal.2005866

Klymkowsky, M. W., and Savagner, P. (2009). Epithelial-mesenchymal transition: a cancer researcher's conceptual friend and foe. Am. J. Pathol. 174, 1588-1593.

Kolasinska-Zwierz, P., Down, T., Latorre, I., Liu, T., Liu, X. S., and Ahringer, J. (2009). Differential chromatin marking of introns and expressed exons by H3K36me3. Nat. Genet. 41, 376-381. doi: 10.1038/ng.322

Kortylewski, M., Xin, H., Kujawski, M., Lee, H., Liu, Y., Harris, T., et al. (2009). Regulation of the IL-23 and IL-12 balance by Stat 3 signaling in the tumor microenvironment. Cancer Cell 15, 114-123. doi: 10.1016/j.ccr.2008.12.018
Laemmle, A., Lechleiter, A., Roh, V., Schwarz, C., Portmann, S., Furer, C., et al. (2012). Inhibition of SIRT1 impairs the accumulation and transcriptional activity of HIF-1 $\alpha$ protein under hypoxic conditions. PLoS One 7:e33433. doi: 10.1371/journal.pone.0033433

Lan, T., Li, H., Zhang, D., Xu, L., Liu, H., Hao, X., et al. (2019). KIAA1429 contributes to liver cancer progression through N6-methyladenosinedependent post-transcriptional modification of GATA3. Mol. Cancer $18: 186$.

Lee, S. H., Shin, M. S., Lee, H. S., Bae, J. H., Lee, H. K., Kim, H. S., et al. (2001). Expression of Fas and Fas-related molecules in human hepatocellular carcinoma. Hum. Pathol. 32, 250-256. doi: 10.1053/hupa.2001.22769

Leitner, L., Shaposhnikov, D., Mengel, A., Descot, A., Julien, S., Hoffmann, R., et al. (2011). MAL/MRTF-A controls migration of non-invasive cells by upregulation of cytoskeleton-associated proteins. J. Cell Sci. 124, 4318-4331. doi: 10.1242/jcs. 092791

Leong, T. Y., and Leong, A. S. (2005). Epidemiology and carcinogenesis of hepatocellular carcinoma. НPB 7, 5-15. doi: 10.1080/13651820410024021

Li, J., Zhu, L., Shi, Y., Liu, J., Lin, L., and Chen, X. (2019). M6A demethylase FTO promotes hepatocellular carcinoma tumorigenesis via mediating PKM2 demethylation. Am. J. Transl. Res. 11, 6084-6092.

Li, X., Xiong, X., and Yi, C. (2016). Epitranscriptome sequencing technologies: decoding RNA modifications. Nat. Methods. 14, 23-31. doi: 10.1038/nmeth. 4110

Li, Z., Zhang, J., Liu, X., Li, S., Wang, Q., Di, C., et al. (2018). The LINC01138 drives malignancies via activating arginine methyltransferase 5 in hepatocellular carcinoma. Nat. Commun. 9:1572.

Libbrecht, L., Desmet, V., and Roskams, T. (2005). Preneoplastic lesions in human hepatocarcinogenesis. Liver Int. 25, 16-27. doi: 10.1111/j.1478-3231.2005. 01016.x

Linder, B., Grozhik, A. V., Olarerin-George, A. O., Meydan, C., Mason, C. E., and Jaffrey, S. R. (2015). Single-nucleotide-resolution mapping of m6A and m6Am throughout the transcriptome. Nat. Methods. 12, 767-772. doi: 10.1038/nmeth. 3453

Liu, K., and Chen, W. (2020). iMRM: a platform for simultaneously identifying multiple kinds of RNA modifications. Bioinformatics (Oxford, England) 36, 3336-3342. doi: 10.1093/bioinformatics/btaa155

Liu, N., Dai, Q., Zheng, G., He, C., Parisien, M., and Pan, T. (2015). N(6)methyladenosine-dependent RNA structural switches regulate RNA-protein interactions. Nature 518, 560-564. doi: 10.1038/nature14234

Liu, N., Parisien, M., Dai, Q., Zheng, G., He, C., and Pan, T. (2013). Probing N6-methyladenosine RNA modification status at single nucleotide resolution in mRNA and long noncoding RNA. RNA 19, 1848-1856. doi: 10.1261/rna. 041178.113

Liu, N., Zhou, K. I., Parisien, M., Dai, Q., Diatchenko, L., and Pan, T. J. (2017). N 6methyladenosine alters RNA structure to regulate binding of a low-complexity protein. Nucleic Acids Res. 45, 6051-6063. doi: 10.1093/nar/gkx141

Liu, S., Li, G., Li, Q., Zhang, Q., Zhuo, L., Chen, X., et al. (2020a). The roles and mechanisms of YTH domain-containing proteins in cancer development and progression. Am. J. Cancer Res. 10, 1068-1084.

Liu, S., Zhu, A., He, C., and Chen, M. (2020b). REPIC: a database for exploring the N6-methyladenosine methylome. Genome Biol. 21:100.

Liu, X., Liu, J., Xiao, W., Zeng, Q., Bo, H., Zhu, Y., et al. (2020c). SIRT1 regulates $\mathrm{N}(6)$-methyladenosine RNA modification in hepatocarcinogenesis by inducing RANBP2-dependent FTO SUMOylation. Hepatology (Baltimore, Md) 72, 20292050.

Llovet, J. M., and Bruix, J. (2008). Molecular targeted therapies in hepatocellular carcinoma. Hepatology (Baltimore, Md). 48, 1312-1327.

Llovet, J. M., Ricci, S., Mazzaferro, V., Hilgard, P., Gane, E., Blanc, J. F., et al. (2008). Sorafenib in advanced hepatocellular carcinoma. N. Engl. J. Med. 359, 378-390.

Lu, D.-H., Lv, W.-W., Li, W.-X., and Gao, Y.-D. (2018). High PKM2 expression is independently correlated with decreased overall survival in hepatocellular carcinoma. Oncol. Lett. 16, 3603-3610.

Luo, X., Li, H., Liang, J., Zhao, Q., Xie, Y., Ren, J., et al. (2020). RMVar: an updated database of functional variants involved in RNA modifications. Nucleic Acids Res. 49, D1405-D1412.

Luo, X., Zhou, N., Wang, L., Zeng, Q., and Tang, H. (2019). Long noncoding RNA GATA3-AS1 promotes cell proliferation and metastasis in hepatocellular 
carcinoma by suppression of PTEN, CDKN1A, and TP53. Can. J. Gastroenterol. Hepatol. 2019:1389653.

Ma, J. Z., Yang, F., Zhou, C. C., Liu, F., Yuan, J. H., Wang, F., et al. (2017). METTL14 suppresses the metastatic potential of hepatocellular carcinoma by modulating $\mathrm{N}(6)$-methyladenosine-dependent primary MicroRNA processing. Hepatology (Baltimore, Md). 65, 529-543. doi: 10.1002/hep.28885

Maity, A., and Das, B. (2016). N6-methyladenosine modification in mRNA: machinery, function and implications for health and diseases. FEBS J. 283, 1607-1630. doi: 10.1111/febs.13614

Makarova-Rusher, O. V., Medina-Echeverz, J., Duffy, A. G., and Greten, T. F. (2015). The yin and yang of evasion and immune activation in HCC. J. Hepatol. 62, 1420-1429. doi: 10.1016/j.jhep.2015.02.038

Manning, B. D., and Toker, A. (2017). AKT/PKB signaling: navigating the network. Cell 169, 381-405. doi: 10.1016/j.cell.2017.04.001

Martinez, L. A. (2016). Mutant p53 and ETS2, a Tale of Reciprocity. Front. Oncol. 6:35. doi: 10.3389/fonc. 2016.00035

Matsuzaki, K., Date, M., Furukawa, F., Tahashi, Y., Matsushita, M., Sakitani, K., et al. (2000). Autocrine stimulatory mechanism by transforming growth factor beta in human hepatocellular carcinoma. Cancer Res. 60, 1394-1402.

Meyer Kate, D., Saletore, Y., Zumbo, P., Elemento, O., Mason Christopher, E., and Jaffrey Samie, R. (2012). Comprehensive Analysis of mRNA Methylation Reveals Enrichment in 3\&\#x2032. UTRs and near Stop Codons. Cell 149, 1635-1646.

Mínguez, B., and Lachenmayer, A. (2011). Diagnostic and prognostic molecular markers in hepatocellular carcinoma. Dis. Markers 31, 181-190. doi: 10.1155/ 2011/310675

Molinie, B., Wang, J., Lim, K. S., Hillebrand, R., Lu, Z-x, Van Wittenberghe, N., et al. (2016). m6A-LAIC-seq reveals the census and complexity of the m6A epitranscriptome. Nat. Methods 13, 692-698. doi: 10.1038/nmeth.3898

Morell, C. M., and Strazzabosco, M. (2014). Notch signaling and new therapeutic options in liver disease. J. Hepatol. 60, 885-890. doi: 10.1016/j.jhep.2013.11.028

Mott, J. L., and Gores, G. J. (2007). Piercing the armor of hepatobiliary cancer: Bcl2 homology domain 3 (BH3) mimetics and cell death. Hepatology (Baltimore, Md). 46, 906-911. doi: 10.1002/hep.21812

Müller, S., Glaß, M., Singh, A. K., Haase, J., Bley, N., Fuchs, T., et al. (2019). IGF2BP1 promotes SRF-dependent transcription in cancer in a m6A- and miRNA-dependent manner. Nucleic Acids Res. 47, 375-390. doi: 10.1093/nar/ gky1012

Myers, E., Hill, A. D., Kelly, G., McDermott, E. W., O’Higgins, N. J., Buggy, Y., et al. (2005). Associations and interactions between Ets-1 and Ets-2 and coregulatory proteins, SRC-1, AIB1, and NCoR in breast cancer. Clin. Cancer Res. 11, 2111-2122. doi: 10.1158/1078-0432.ccr-04-1192

Nalesnik, M. A., Tseng, G., Ding, Y., Xiang, G.-S., Zheng, Z-l, Yu, Y., et al. (2012). Gene deletions and amplifications in human hepatocellular carcinomas: correlation with hepatocyte growth regulation. Am. J. Pathol. 180, 1495-1508. doi: 10.1016/j.ajpath.2011.12.021

Nault, J.-C., Ningarhari, M., Rebouissou, S., and Zucman-Rossi, J. (2019). The role of telomeres and telomerase in cirrhosis and liver cancer. Nat. Rev. Gastroenterol. Hepatol. 16, 544-558. doi: 10.1038/s41575-019-0165-3

Nie, F., Feng, P., Song, X., Wu, M., Tang, Q., and Chen, W. (2020). RNAWRE: a resource of writers, readers and erasers of RNA modifications. Database (Oxford) 2020:baaa049.

Niu, Z.-S., Niu, X.-J., and Wang, W.-H. (2016). Genetic alterations in hepatocellular carcinoma: An update. World J. Gastroenterol. 22, 9069-9095. doi: 10.3748/wjg.v22.i41.9069

Oda, N., Abe, M., and Sato, Y. (1999). ETS-1 converts endothelial cells to the angiogenic phenotype by inducing the expression of matrix metalloproteinases and integrin $\beta 3$. J. Cell. physiol. 178, 121-132. doi: 10.1002/(sici)10974652(199902)178:2<121::aid-jcp1>3.0.co;2-f

Okada, H., Honda, M., Campbell, J. S., Takegoshi, K., Sakai, Y., Yamashita, T., et al. (2015). Inhibition of microRNA-214 ameliorates hepatic fibrosis and tumor incidence in platelet-derived growth factor C transgenic mice. Cancer Sci. 106, 1143-1152. doi: $10.1111 /$ cas. 12730

Okamura, K., Yamashita, S., Ando, H., Horibata, Y., Aoyama, C., Takagishi, K., et al. (2009). Identification of nuclear localization and nuclear export signals in Ets2, and the transcriptional regulation of Ets2 and CTP:phosphocholine cytidylyltransferase alpha in tetradecanoyl-13-acetate or macrophage-colony stimulating factor stimulated RAW264 cells. Biochim. Biophys. Acta 1791, 173-182. doi: 10.1016/j.bbalip.2008.12.016

Ping, X. L., Sun, B. F., Wang, L., Xiao, W., Yang, X., Wang, W. J., et al. (2014). Mammalian WTAP is a regulatory subunit of the RNA N6-methyladenosine methyltransferase. Cell Res. 24, 177-189. doi: 10.1038/cr.2014.3

Qian, B. Z., and Pollard, J. W. (2010). Macrophage diversity enhances tumor progression and metastasis. Cell 141,39-51. doi: 10.1016/j.cell.2010.03.014

Qiu, X., Zheng, J., Guo, X., Gao, X., Liu, H., Tu, Y., et al. (2013). Reduced expression of SOCS2 and SOCS6 in hepatocellular carcinoma correlates with aggressive tumor progression and poor prognosis. Mol. Cell. Biochem. 378, 99-106. doi: 10.1007/s11010-013-1599-5

Rao, C. V., Asch, A. S., and Yamada, H. Y. (2017). Frequently mutated genes/pathways and genomic instability as prevention targets in liver cancer. Carcinogenesis 38, 2-11. doi: 10.1093/carcin/bgw118

Reddy, J. K., Rao, S., and Moody, D. E. (1976). Hepatocellular carcinomas in acatalasemic mice treated with nafenopin, a hypolipidemic peroxisome proliferator. Cancer Res. 36, 1211-1217.

Rico-Bautista, E., Flores-Morales, A., and Fernández-Pérez, L. (2006). Suppressor of cytokine signaling (SOCS) 2, a protein with multiple functions. Cytokine Growth Factor Rev. 17, 431-439. doi: 10.1016/j.cytogfr.2006.09.008

Roundtree, I. A., and He, C. (2016). Nuclear m(6)A reader YTHDC1 regulates mRNA splicing. Trends Genet. TIG 32, 320-321. doi: 10.1016/j.tig.2016.03.006

Sever, R., and Brugge, J. S. (2015). Signal transduction in cancer. Cold Spring Harb. Perspect. Med. 5:a006098.

Shahjee, H. M., and Bhattacharyya, N. (2014). Activation of various downstream signaling molecules by IGFBP-3. J. Cancer Ther. 5, 830-835. doi: 10.4236/jct. 2014.59091

Sharrocks, A. D. (2001). The ETS-domain transcription factor family. Nat. Rev. Mol. Cell Biol. 2, 827-837.

Shen, S., Dean, D. C., Yu, Z., and Duan, Z. (2019). Role of cyclin-dependent kinases (CDKs) in hepatocellular carcinoma: therapeutic potential of targeting the CDK signaling pathway. Hepatol. Res. 49, 1097-1108. doi: 10.1111/hepr.13353

Siddiqui, M. T., Seydafkan, S., and Cohen, C. (2014). GATA3 expression in metastatic urothelial carcinoma in fine needle aspiration cell blocks: A review of 25 cases. Diagn. Cytopathol. 42, 809-815. doi: 10.1002/dc.23131

Singh, A. K., Kumar, R., and Pandey, A. K. (2018). Hepatocellular carcinoma: causes, mechanism of progression and biomarkers. Curr. Chem. Genom. Transl. Med. 12, 9-26. doi: 10.2174/2213988501812010009

Śledź, P., and Jinek, M. (2016). Structural insights into the molecular mechanism of the m(6)A writer complex. Elife 5:e18434.

Stanaway, J. D., Flaxman, A. D., Naghavi, M., Fitzmaurice, C., Vos, T., Abubakar, I., et al. (2016). The global burden of viral hepatitis from 1990 to 2013: findings from the Global Burden of Disease Study 2013. Lancet (London, England) 388, 1081-1088.

Strahl, B. D., and Allis, C. D. (2000). The language of covalent histone modifications. Nature 403, 41-45. doi: 10.1038/47412

Strazzabosco, M., and Fabris, L. (2012). Notch signaling in hepatocellular carcinoma: guilty in association! Gastroenterology 143, 1430-1434. doi: 10. 1053/j.gastro.2012.10.025

Suzuki, M. M., and Bird, A. (2008). DNA methylation landscapes: provocative insights from epigenomics. Nat. Rev. Genet. 9, 465-476. doi: 10.1038/nrg2341

Tachibana, K., Yamasaki, D., Ishimoto, K., and Doi, T. (2008). The role of PPARs in cancer. PPAR Res. 2008:102737.

Tang, Y., Chen, K., Song, B., Ma, J., Wu, X., Xu, Q., et al. (2020). m6A-Atlas: a comprehensive knowledgebase for unraveling the N6-methyladenosine (m6A) epitranscriptome. Nucleic Acids Res. 49, D134-D143.

Tetsu, O., and McCormick, F. (2017). ETS-targeted therapy: can it substitute for MEK inhibitors? Clin. Transl. Med. 6:16.

Tilgner, H., Nikolaou, C., Althammer, S., Sammeth, M., Beato, M., Valcárcel, J., et al. (2009). Nucleosome positioning as a determinant of exon recognition. Nat. Struct. Mol. Biol. 16, 996-1001. doi: 10.1038/nsmb.1658

Tiniakos, D., Spandidos, D. A., Kakkanas, A., Pintzas, A., Pollice, L., and Tiniakos, G. (1989). Expression of ras and myc oncogenes in human hepatocellular carcinoma and non-neoplastic liver tissues. Anticancer Res. 9, 715-721.

Vander Heiden, M. G., Cantley, L. C., and Thompson, C. B. (2009). Understanding the Warburg effect: the metabolic requirements of cell proliferation. Science 324, 1029-1033. doi: 10.1126/science.1160809 
Wagner, N., and Wagner, K.-D. (2020). PPAR Beta/Delta and the hallmarks of cancer. Cells 9:1133. doi: 10.3390/cells9051133

Wang, D., Zheng, X., Fu, B., Nian, Z., Qian, Y., Sun, R., et al. (2019). Hepatectomy promotes recurrence of liver cancer by enhancing IL-11-STAT3 signaling. EBioMedicine 46, 119-132. doi: 10.1016/j.ebiom.2019.07.058

Wang, N., Zhong, C., Fu, M., Li, L., Wang, F., Lv, P., et al. (2019). Long non-coding RNA HULC promotes the development of breast cancer through regulating LYPD1 expression by sponging miR-6754-5p. OncoTargets Ther. 12, 1067110679. doi: $10.2147 /$ ott.s226040

Wang, P., Doxtader, K. A., and Nam, Y. (2016). Structural basis for cooperative function of Mettl3 and Mettl14 methyltransferases. Mol. Cell 63, 306-317. doi: 10.1016/j.molcel.2016.05.041

Wang, X., Lu, Z., Gomez, A., Hon, G. C., Yue, Y., Han, D., et al. (2014). N6methyladenosine-dependent regulation of messenger RNA stability. Nature 505, 117-120. doi: 10.1038/nature12730

Wang, X., Zhao, B. S., Roundtree, I. A., Lu, Z., Han, D., Ma, H., et al. (2015). $\mathrm{N}(6)$-methyladenosine modulates messenger RNA translation efficiency. Cell 161, 1388-1399. doi: 10.1016/j.cell.2015.05.014

Wang, Y., and Zhou, B. P. (2013). Epithelial-mesenchymal transition-a hallmark of breast cancer metastasis. Cancer Hallm. 1, 38-49. doi: 10.1166/ch.2013.1004

Ward, P. S., and Thompson, C. B. (2012). Metabolic reprogramming: a cancer hallmark even warburg did not anticipate. Cancer Cell 21, 297-308. doi: 10. 1016/j.ccr.2012.02.014

Wei, C. M., Gershowitz, A., and Moss, B. (1975). Methylated nucleotides block 5 ' terminus of HeLa cell messenger RNA. Cell 4, 379-386. doi: 10.1016/00928674(75) $90158-0$

Wilking, M. J., and Ahmad, N. (2015). The role of SIRT1 in cancer: the saga continues. Am. J. Pathol. 185, 26-28.

Wu, B., Su, S., Patil, D. P., Liu, H., Gan, J., Jaffrey, S. R., et al. (2018). Molecular basis for the specific and multivariant recognitions of RNA substrates by human hnRNP A2/B1. Nat. Commun. 9:420.

Wu, R., Jiang, D., Wang, Y., and Wang, X. (2016). N6-methyladenosine (m6A) methylation in mRNA with a dynamic and reversible epigenetic modification. Mol. Biotechnol. 58, 450-459. doi: 10.1007/s12033-016-9947-9

Xu, F., Jin, T., Zhu, Y., and Dai, C. (2018). Immune checkpoint therapy in liver cancer. J. Exp. Clin. Cancer Res. 37:110.

Xu, H., Wang, H., Zhao, W., Fu, S., Li, Y., Ni, W., et al. (2020). SUMO1 modification of methyltransferase-like 3 promotes tumor progression via regulating Snail mRNA homeostasis in hepatocellular carcinoma. Theranostics 10, 5671-5686. doi: 10.7150/thno.42539

Yamamoto, T., Seino, Y., Fukumoto, H., Koh, G., Yano, H., Inagaki, N., et al. (1990). Over-expression of facilitative glucose transporter genes in human cancer. Biochem. Biophys. Res. Commun. 170, 223-230. doi: 10.1016/0006-291x(90) 91263-r

Yang, J. D., and Roberts, L. R. (2010). Hepatocellular carcinoma: a global view. Nat. Rev. Gastroenterol. Hepatol. 7, 448-458. doi: 10.1038/nrgastro.2010. 100

Yang, S. L., Liu, L. P., Jiang, J. X., Xiong, Z. F., He, Q. J., and Wu, C. (2014). The correlation of expression levels of HIF-1 $\alpha$ and HIF- $2 \alpha$ in hepatocellular carcinoma with capsular invasion, portal vein tumor thrombi and patients' clinical outcome. Jpn J. Clin. Oncol. 44, 159-167. doi: 10.1093/ jjco/hyt194

Yang, Y., Xin, X., Fu, X., and Xu, D. (2018). Expression pattern of human SERPINE2 in a variety of human tumors. Oncol. Lett. 15, breakpgrng4523-4530.

Yoshikawa, H., Matsubara, K., Qian, G.-S., Jackson, P. E., Groopman, J., Manning, J., et al. (2001). SOCS-1, a negative regulator of the JAK/STAT pathway, is silenced by methylation in human hepatocellular carcinoma and shows growth-suppression activity. Nat. Genet. 28, 29-35. doi: 10.1038/ng0501-29

Yu, L.-X., Ling, Y., and Wang, H.-Y. (2018). Role of nonresolving inflammation in hepatocellular carcinoma development and progression. NPJ Prec. Oncol. 2:6.

Yumoto, E., Nakatsukasa, H., Hanafusa, T., Yumoto, Y., Nouso, K., Matsumoto, E., et al. (2005). IGFBP-3 expression in hepatocellular carcinoma involves abnormalities in TGF-beta and/or Rb signaling pathways. Int. J. Oncol. 27, 1223-1230.

Zaccara, S., Ries, R. J., and Jaffrey, S. R. (2019). Reading, writing and erasing mRNA methylation. Nat. Rev. Mol. Cell Biol. 20, 608-624. doi: 10.1038/s41580-0190168-5

Zappala, G., Elbi, C., Edwards, J., Gorenstein, J., Rechler, M. M., and Bhattacharyya, N. (2008). Induction of apoptosis in human prostate cancer cells by insulinlike growth factor binding protein-3 does not require binding to retinoid $\mathrm{X}$ receptor-alpha. Endocrinology 149, 1802-1812. doi: 10.1210/en.2007-1315

Zarnack, K., König, J., Tajnik, M., Martincorena, I., Eustermann, S., Stévant, I., et al. (2013). Direct competition between hnRNP C and U2AF65 protects the transcriptome from the exonization of Alu elements. Cell 152, 453-466. doi: 10.1016/j.cell.2012.12.023

Zhai, J., Song, J., Zhang, T., Xie, S., and Ma, C. (2020). deepEA: a containerized web server for interactive analysis of epitranscriptome sequencing data. Plant Physiol. 185, 29-33.

Zhang, C., Fu, J., and Zhou, Y. (2019). A review in research progress concerning m6A methylation and immunoregulation. Front. Immunol. 10:922. doi: 10. 3389/fimmu.2019.00922

Zhang, Y., and Hamada, M. (2020). MoAIMS: efficient software for detection of enriched regions of MeRIP-Seq. BMC Bioinformatics. 21:103. doi: 10.1186/ s12859-020-3430-0

Zhao, C., Li, Y., Zhang, M., Yang, Y., and Chang, L. (2015). miR-126 inhibits cell proliferation and induces cell apoptosis of hepatocellular carcinoma cells partially by targeting Sox2. Hum. Cell 28, 91-99. doi: 10.1007/s13577-0140105-z

Zhao, X., Chen, Y., Mao, Q., Jiang, X., Jiang, W., Chen, J., et al. (2018). Overexpression of YTHDF1 is associated with poor prognosis in patients with hepatocellular carcinoma. Cancer Biomarkers 21, 1-10.

Zhao, Y., Shi, Y., Shen, H., and Xie, W. (2020). m6A-binding proteins: the emerging crucial performers in epigenetics. J. Hematol. Oncol. 13:35.

Zheng, G., Dahl, J. A., Niu, Y., Fedorcsak, P., Huang, C. M., Li, C. J., et al. (2013). ALKBH5 is a mammalian RNA demethylase that impacts RNA metabolism and mouse fertility. Mol. Cell 49, 18-29. doi: 10.1016/j.molcel.2012.10.015

Zheng, R., and Blobel, G. A. (2010). GATA transcription factors and cancer. Genes Cancer 1, 1178-1188. doi: 10.1177/1947601911404223

Zhong, L., Liao, D., Zhang, M., Zeng, C., Li, X., Zhang, R., et al. (2019). YTHDF2 suppresses cell proliferation and growth via destabilizing the EGFR mRNA in hepatocellular carcinoma. Cancer Lett. 442, 252-261. doi: 10.1016/j.canlet. 2018.11.006

Conflict of Interest: The authors declare that the research was conducted in the absence of any commercial or financial relationships that could be construed as a potential conflict of interest.

Copyright (๑) 2021 Sivasudhan, Blake, Lu, Meng and Rong. This is an open-access article distributed under the terms of the Creative Commons Attribution License (CC BY). The use, distribution or reproduction in other forums is permitted, provided the original author(s) and the copyright owner(s) are credited and that the original publication in this journal is cited, in accordance with accepted academic practice. No use, distribution or reproduction is permitted which does not comply with these terms. 